\title{
Laparoscopic Herniotomy in Female Children: Our Experience in 110 Patients
}

\author{
Chalapathi Gontumukkala ${ }^{1}$, Ramana NG Venkata ${ }^{2}$, Rajeev K Golimi ${ }^{3}$, Veera S Javvadi ${ }^{4}$
}

\begin{abstract}
Aim of the study: To assess the results and complications of laparoscopic herniotomy in female children using percutaneous internal ring suturing (PIRS).

Materials and methods: One hundred and ten consecutive female children who were admitted with a unilateral or bilateral inguinal hernia from January 2015 to June 2018 to a medical college referral hospital were included in the study. The technique used was PIRS, using spinal needle 23 gaze and 3.0 prolene. All patients were followed up postoperatively. Babies with recurrent hernias and complicated inguinal hernia were excluded from this study.

Results: A total of 110 female children with unilateral or bilateral inguinal hernia were included in the study. Age ranged from 1 month to 15 years with a mean age of 3 years. The clinically unilateral hernia was present in 80 children but the patent internal ring was present on the contralateral side in 25 children and was repaired simultaneously. The bilateral inguinal hernia was present in 30 children. The total number of hernia units was 165 . The mean operative time was 15 minutes, ranging from 12 minutes to 20 minutes for unilateral hernia and $15-30$ minutes for a bilateral hernia. The mean postoperative stay was 1 day. The follow-up period ranged from 7 days to 2 years. Two babies had hematoma at the internal ring during the procedure, subsided with no postoperative sequel. One child developed hernia on contralateral side, who was operated for contralateral patent ring during repair of an ipsilateral clinical hernia. None other children who were operated for clinical hernia had a recurrence.

Conclusion: Laparoscopic herniotomy using the technique of PIRS is safe, quick with minimal postoperative pain, and short hospital stay, and had a very low incidence of recurrence.

Keywords: Hernia, Laparoscopy, Percutaneous internal ring suturing.

World Journal of Laparoscopic Surgery (2019): 10.5005/jp-journals-10033-1375
\end{abstract}

\section{INTRODUCTION}

Inguinal hernias in children are due to the protrusion of viscera through persistent process vaginalis. Conventional open therapy includes ligation of the sac at the internal ring. The same basic principle is used in laparoscopy also. Conventional open therapy has a high success rate and acceptable cosmetic results with few complications. ${ }^{1}$ The main drawbacks of conventional open therapy are the inability to rule out the contralateral patent processes vaginalis and synchronous hernia. Nowadays, laparoscopy in children is increasingly used to repair inguinal hernias. Several laparoscopic techniques have developed over the past two decades aimed at improving the outcome. ${ }^{2}$ This study is to assess the technique, results, complications of percutaneous internal ring suturing (PIRS) with the help of spinal needle 23 gaze, and 3.0 prolene.

\section{Materials and Methods}

This was a prospective study conducted in the department of pediatric surgery. A total of 1,100 children with inguinal hernia were admitted for surgery from January 2015 to June 2018 to a medical college referral hospital. Out of the total 1,100 children with inguinal hernia, male children were 990 and female children were 110. These 110 female children with unilateral or bilateral inguinal hernia were chosen for this procedure. Consent was taken from all parents before the procedure. The technique used was PIRS using spinal needle 23 gaze and 3.0 prolene. All patients were followed up postoperatively. Male children with inguinal hernias and female babies with recurrent hernias and complicated inguinal hernias were excluded from this study.

\author{
${ }^{1-4}$ Department of Paediatric Surgery, Kurnool Medical College \\ Kurnool, Andhra Pradesh, India
}

Corresponding Author: Veera S Javvadi, Department of Paediatric Surgery, Kurnool Medical College, Kurnool, Andhra Pradesh, India, Phone: +91 9440439674, e-mail: chalagontu@gmail.com

How to cite this article: Gontumukkala C, Venkata RNG, Golimi RK, et al. Laparoscopic Herniotomy in Female Children: Our Experience in 110 Patients. World J Lap Surg 2019;12(2):68-72.

Source of support: Department of Paediatric Surgery, Kurnool Medical College, Kurnool, Andhra Pradesh, India

Conflict of interest: None

\section{Procedure}

Laparoscopic repair is performed under general anesthesia. The patient is positioned supine, often in the Trendelenburg position. The surgeon stands on the side contralateral to the hernia with the monitor on the ipsilateral side. The instruments used are $5 \mathrm{~mm}$ umbilical port for the camera and $3 \mathrm{~mm}$ port on the contralateral iliac fossa for manipulation. The abdomen is insufflated through the umbilicus, to a pressure of $8-12 \mathrm{~mm} \mathrm{Hg}$ depending on the size of the child. Any hernia contents are reduced before beginning the repair of the hernia. With laparoscopy, the contralateral side can be evaluated and bilateral repair performed when necessary.

Following are the steps of the procedure:

- Introduce the 3.0 prolene suture through the barrel of the 22 or 23 gaze spinal needle (Fig. 1).

() The Author(s). 2019 Open Access This article is distributed under the terms of the Creative Commons Attribution 4.0 International License (https://creativecommons. org/licenses/by-nc/4.0/), which permits unrestricted use, distribution, and non-commercial reproduction in any medium, provided you give appropriate credit to the original author(s) and the source, provide a link to the Creative Commons license, and indicate if changes were made. The Creative Commons Public Domain Dedication waiver (http://creativecommons.org/publicdomain/zero/1.0/) applies to the data made available in this article, unless otherwise stated. 


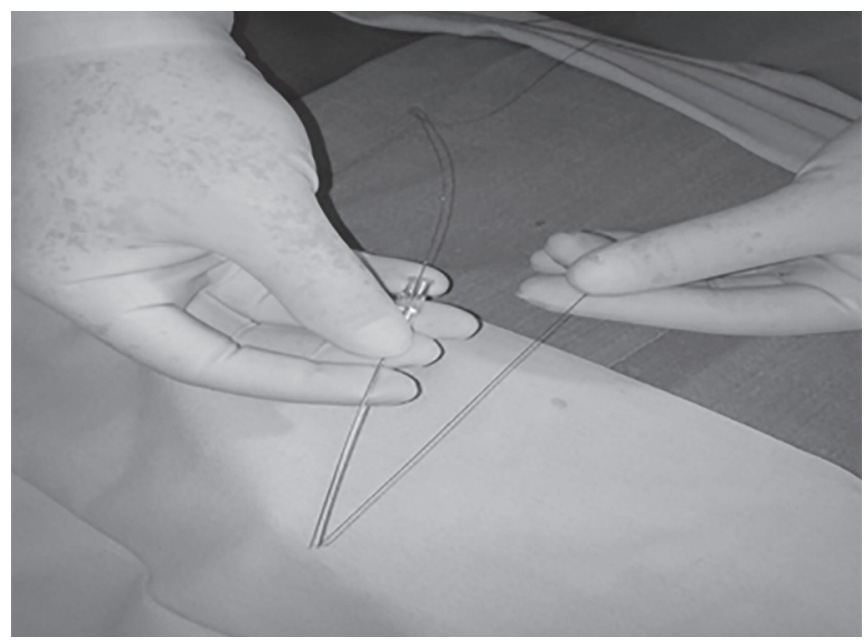

Fig. 1: Preloaded prolene into the spinal needle to make a loop

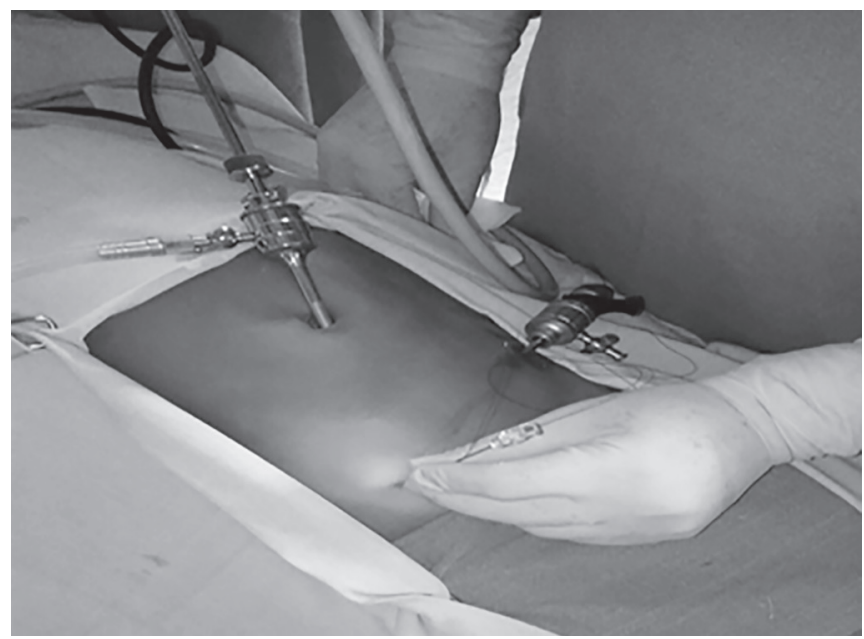

Fig. 3: Insertion of preloaded suture loop into the pre peritoneum from outside

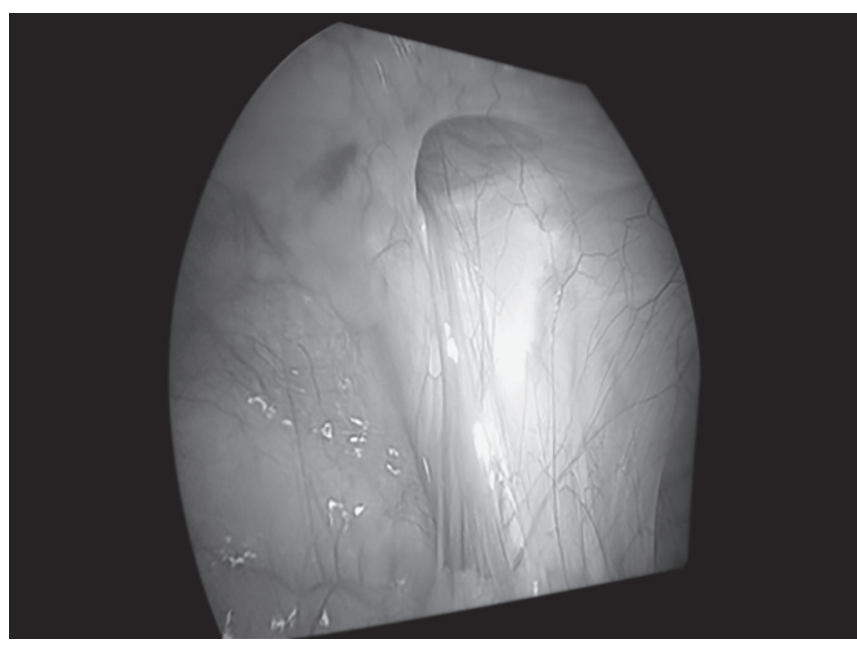

Fig. 2: Laparoscopic view of patent internal ring

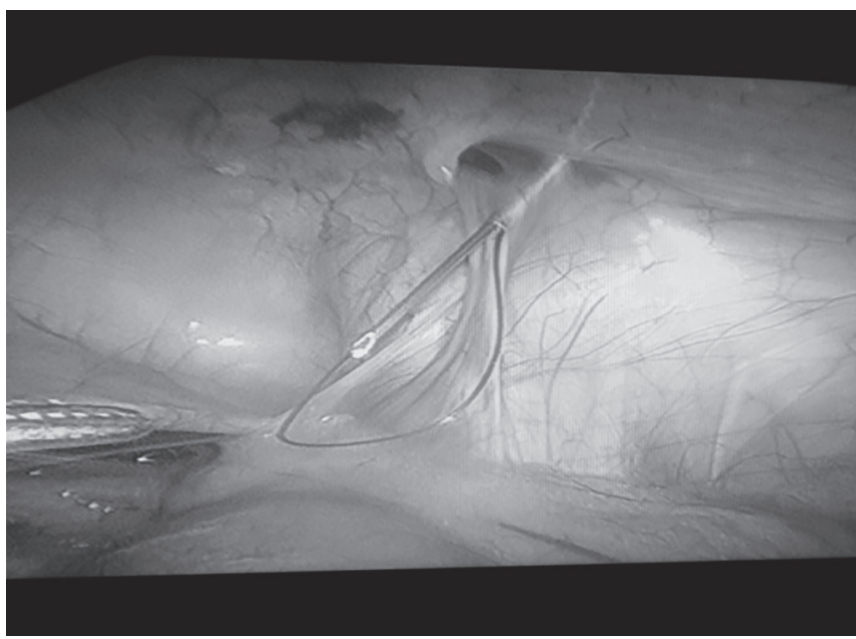

Fig. 4: Needle along with suture loop advanced under the peritoneum around the lateral half of ring and entered the peritoneum at midpoint

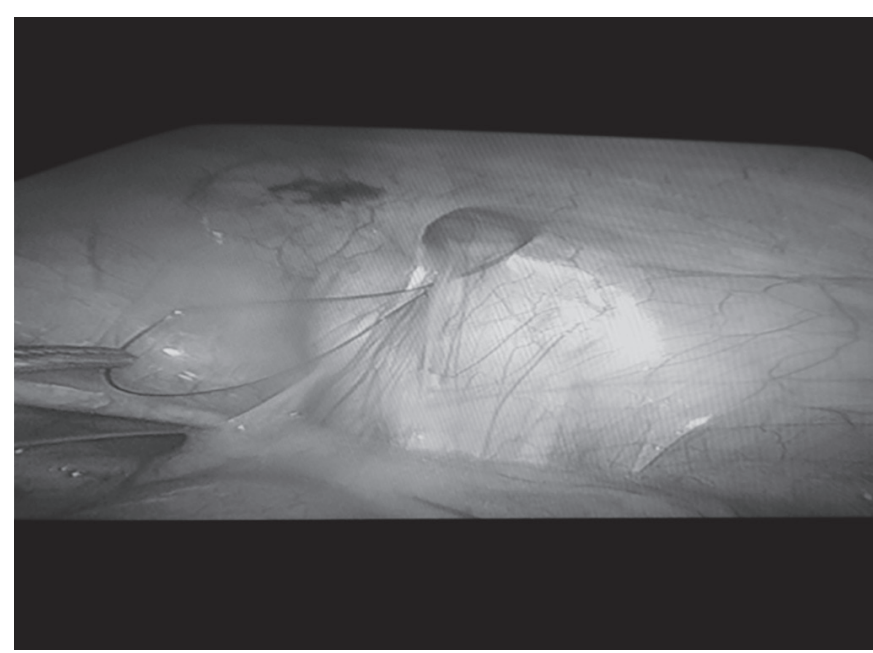

Fig. 5: Needle is withdrawn leaving the suture loop in situ
- Maintaining both ends of the preloaded suture extraperitoneal, advance the needle under the peritoneum around the lateral half of the internal ring (Figs 2 to 4 ).

- Enter the peritoneum and advance the suture into the abdominal cavity, creating a loop (Fig. 4).

- Remove the needle, leaving the loop in place (Fig. 5).

- Advance the needle through the same skin puncture site around the medial half of the ring and enter the peritoneum at the same site of previous loop and pass the needle into the loop of previous suture (Fig. 6).

- Pass prolene suture through barrel needle into the loop (Fig. 6).

- Withdraw the needle leaving prolene suture in the loop (Fig. 7)

- Catch the suture end of the loop outside the abdomen and withdraw them together, now the prolene thread is all around the internal ring (Fig. 8).

- The abdomen is desufflated and any air or fluid in the sac is manually expressed with external compression and tie suture extracorporeally (Fig. 9).

- Now the internal ring is reinspected (Figs 10 and 11). 


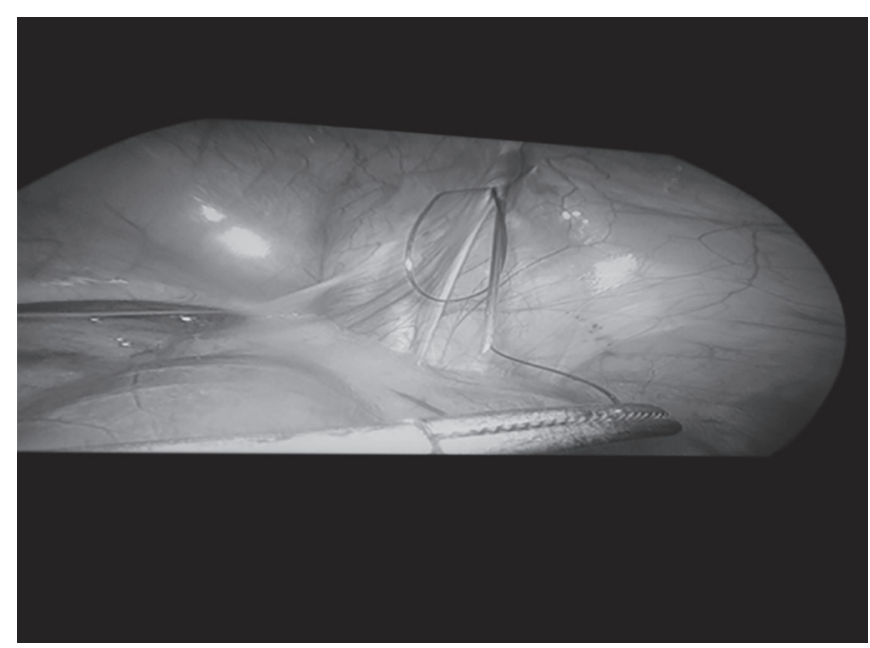

Fig. 6: Now the needle reinserted through the same skin puncture site and advanced around the medial half of the ring and entered the peritoneum at the same site of previous loop and pass the needle and thread into the loop of previous suture

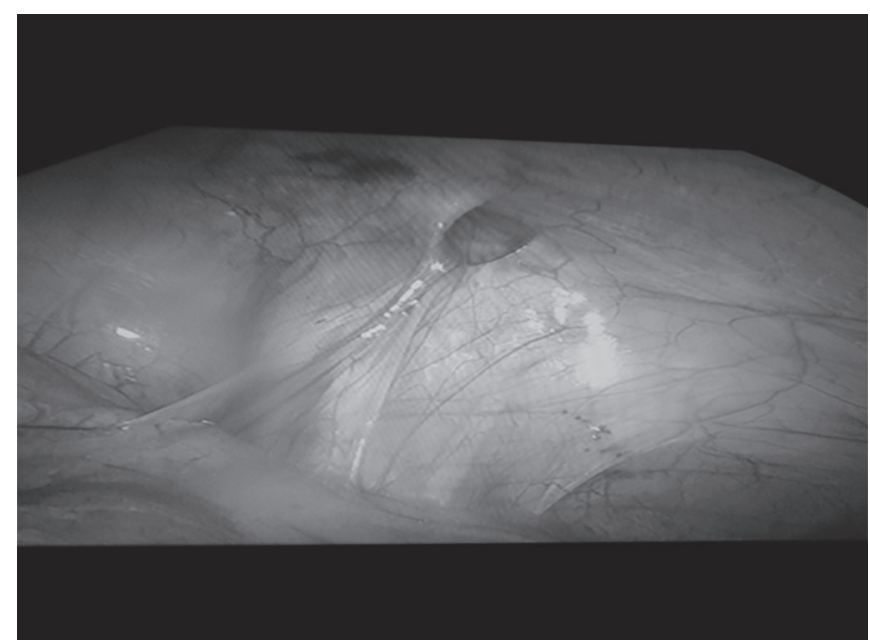

Fig. 8: Loop is pulled from outside, now the prolene thread is all around the internal ring

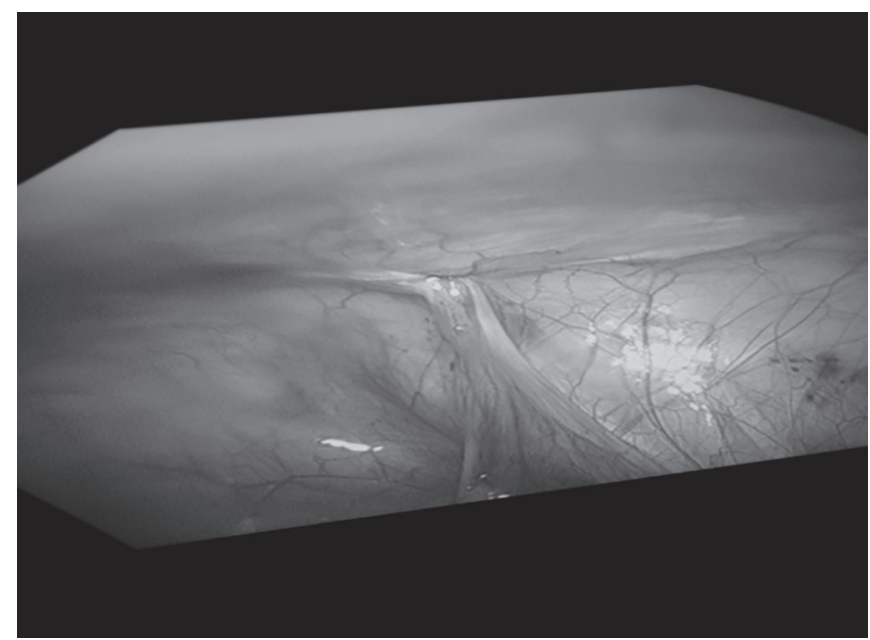

Fig. 10: The internal ring is reinspected

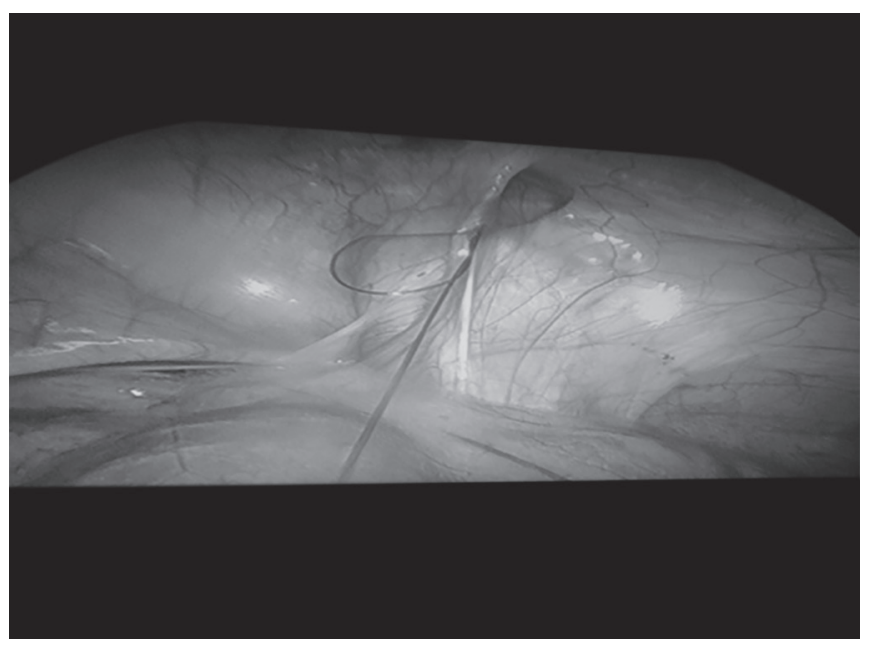

Fig. 7: The needle is withdrawn leaving the thread in situ

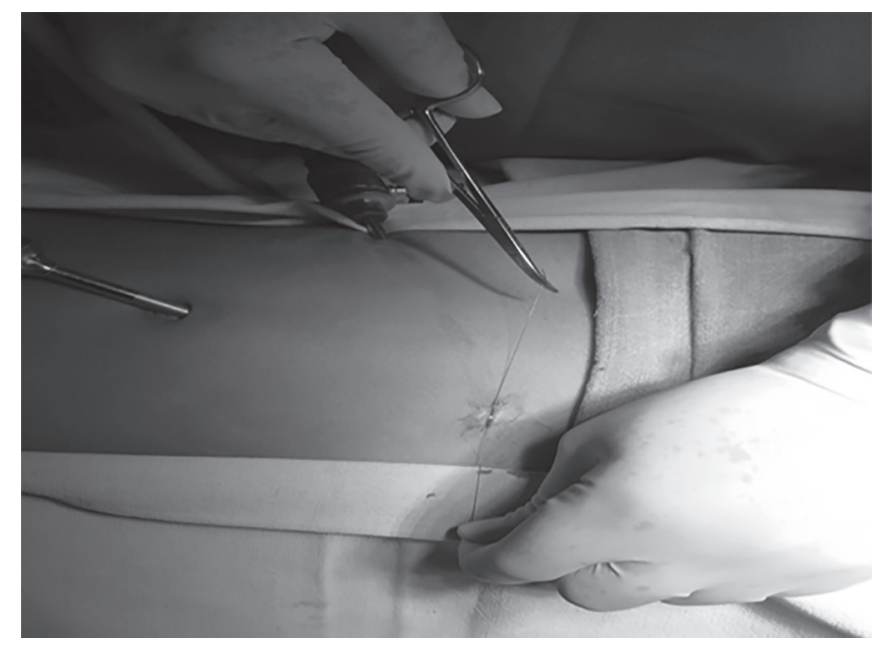

Fig. 9: Pneumoperitoneum deflated and thread is tied outside the abdomen

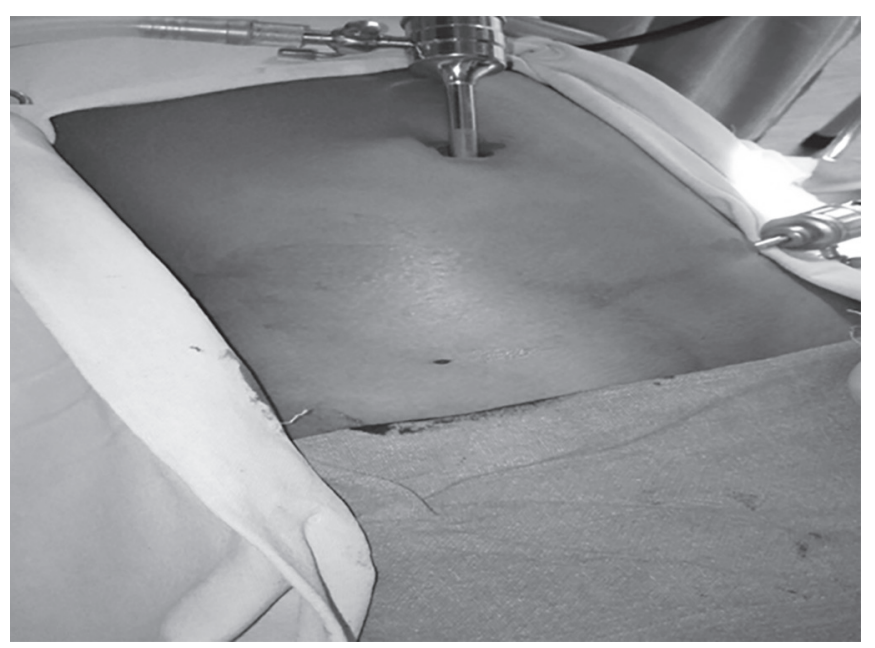

Fig. 11: Appearance after the procedure 


\section{Results}

A total of 110 female children with unilateral or bilateral inguinal hernia were included in the study. Age ranging from 1 month to 15 years. The mean age of 3 years. The clinically unilateral hernia was present in 80 children. The right inguinal hernia was seen in 50 and left inguinal hernia was seen in 30 children. During laparoscopy for unilateral hernias, the patent internal ring was present on the contralateral side in 25 children (31.25\%) and was repaired simultaneously. The bilateral inguinal hernia was present in 30 children. A total number of hernia units was 165. Preoperative ultrasonography was done in all patients to confirm the diagnosis. The mean operative time was 15 minutes, ranging from 12 to 20 minutes for unilateral hernia and 15 to 30 minutes for a bilateral hernia. The mean postoperative stay was 1 day, ranging from 1 day to 3 days. All patients were followed up postoperatively. The follow-up period ranged from 7 days to 2 years. Two babies had hematoma at the internal ring during the procedure and subsided with no postoperative complications. One child had prolene stitch granuloma during follow-up 2 months postoperatively which was removed. One baby developed hernia on the contralateral side who was operated for the contralateral patent ring during the repair of ipsilateral clinical hernia (0.6\%). None other children who were operated for clinical hernia had a recurrence.

\section{Discussion}

The incidence of indirect inguinal hernia in careful controlled population studies is $1-5 \%^{3}$ with male-to-female ratio is 8:1-10:1. The incidence of bilateral inguinal hernia is greater in female patients in all age groups with a reported incidence of $20-50 \%{ }^{4}$ Injury to the reproductive organs during herniotomy in female patients is extremely low so some surgeons advocate bilateral exploration in all female patients.

Laparoscopic repair for inguinal hernias in pediatric patients was first described by El-Gohary. ${ }^{5}$ Laparoscopy-assisted extracorporeal suturing was first described by Prasad et al. ${ }^{6}$ Lee and Yeung used a specially designed herniotomy hook to place suture extraperitoneal around the internal ring and tie it subcutaneously. ${ }^{7}$ Percutaneous internal ring suturing (extracorporeal) was first described by Patkowski et al. ${ }^{8}$ They used 18 gaze needle and 2.0 nonabsorbable suture to accomplish the procedure. We have modified this technique that we use 23 gaze spinal needle and 3.0 prolene. The main advantage of laparoscopy is the inspection of contralateral ring and the diagnosis of ipsilateral hernia and repair of both simultaneously.

A contralateral patient process vaginalis was seen in $31.25 \%$ of our children in contrast with Rathauser and Rowe et al. who have reported contralateral patent process vaginalis in $50-90 \%$ of their patients. ${ }^{9,10}$ Two babies had hematoma during the procedure but subsided postoperatively without any complications.

The reported recurrence rates after conventional open herniorrhaphy among children range from 0.8 to $3.8 \% .^{11}$ The technical errors for the recurrence are (1) failure to find the hernial sac, (2) insufficient low-level ligation of the sac, (3) injury to the floor of the inguinal canal due to operative trauma, (4) failure to close the internal ring in girls, and (5) postoperative wound infection and hematoma. ${ }^{11,12}$ All these technical problems for recurrence can be avoided by laparoscopy. ${ }^{13}$

Though laparoscopic herniotomy theoretically provides high ligation of the hernia sac more proximally than does open repair, higher rates of recurrence have been reported with a laparoscopic procedure. Schier et al. and Chinnaswamy et al. reported the recurrence rate of 3.1-4.4\% after intraperitoneal Z-type suture or with simple purse-string suture. ${ }^{14-16}$ This is in contrast with our low recurrence rate of $0.6 \%$ after laparoscopic PIRS. We had one baby developing clinical hernia (0.6\%) who was operated for contralateral patent ring during ipsilateral clinical hernia. The reason for recurrence may be due to a small patent contralateral ring and was technically difficult to encircle ring completely with suture.

Verma et al. ${ }^{17}$ operated 150 cases of inguinal hernias and hydroceles using laparoscopic herniotomy performing at the neck of the sac. The proximal part of peritoneum was closed with nonabsorbable suture. The mean operative time was 25 minutes for unilateral and 34.8 minutes for bilateral hernias. They have reported the recurrence rate of $1.33 \%$ and a conversion rate of $0.66 \%$.

Spurbeck et al., Kastenberg et al., and others ${ }^{8,18-21}$ used laparoscopic-assisted extraperitoneal circuit suture and reported the recurrence rate ranging from 0 to $4.3 \%$. Some other authors ${ }^{22-25}$ claim the lowest rate of recurrence with a laparoscopic technique involving complete division and then stitching of the hernia sac at an internal inguinal ring. They have reported a recurrence rate ranging from $0 \%$ to $1.3 \%$ which is comparable with our recurrence rate of $0.6 \%$. The low incidence rate in children with PIRS is due to tying the knot outside the peritoneal cavity more securely after desufflation, when compare with intracorporeal suturing in an insufflated abdomen where the positive pressure is working against the closure of the ring.

\section{Conclusion}

Laparoscopic herniotomy using the technique of PIRS using spinal needle 23 gaze is safe, quick with minimal postoperative pain and short hospital stay, had the least rate of complications and associated with a very low incidence of recurrence.

\section{References}

1. Kapur P, Caty MG, Glick PL. Pediatric hernias and hydroceles. Pediatr Clin North Am 1998;45(4):773-789. DOI: 10.1016/S00313955(05)70044-4.

2. Lukong CS. Surgical techniques of laparoscopic inguinal hernia repair in children: a critical appraisal. J Surg Tech Case Rep 2012;4(1):1-5. DOI: 10.4103/2006-8808.100343.

3. Cox JA. Inguinal hernia of childhood. Surg Clin North Am 1985;65(5):1331-1342. DOI: 10.1016/S0039-6109(16)43742-4.

4. Tackett LD, Breuer CK, Luks FL, et al. Incidence of contralateral inguinal hernia: a prospective analysis. J Pediatr Surg 1999;34(5):684-687. DOI: 10.1016/S0022-3468(99)90356-1.

5. El-Gohary MA. Laparoscopic ligation of inguinal hernia in girls. Pediatr Endosurg Innov Tech 1997;1(3):185-188. DOI: 10.1089/pei.1997.1.185.

6. Prasad R, Lovvorn HN, Wadie GM, et al. Early experience with needleoscopic inguinal herniorrhaphy in children. J Pediatr Surg 2003;38(7):1055-1058. DOI: 10.1016/S0022-3468(03)00191-X.

7. Lee KH, Yeung CK. Laparoscopic surgery in newborns and infants: an update. HK J Paediatr 2003;8:327-335.

8. Patkowski D, Czernik J, Chrzan R, et al. Percutaneous internal ring suturing: a simple minimally invasive technique for inguinal hernia repair in children. J Laparoendosc Adv Surg Tech A 2006;16(5): 513-517. DOI: 10.1089/lap.2006.16.513.

9. Rathauser F. Historical overview of the bilateral approach to pediatric inguinal hernias. Am J Surg 1985;150(5):527-532. DOI: 10.1016/00029610(85)90430-1.

10. Rowe MI, Copelson LW, Clatworthy HW. The patent process vaginalis and the inguinal hernia. J Pediatr Surg 1969;4(1):102-107. DOI: 10.1016/0022-3468(69)90189-4. 
11. Steinau G, Treutner KH, Feeken $\mathrm{G}$, et al. Recurrent inguinal hernias in infants and children. World J Surg 1995;19(2):303-306. DOI: 10.1007/ BF00308645.

12. Grosfeld JL, Minnick K, Shedd F, et al. Inguinal hernia in children: factors affecting recurrence in 62 cases. J Pediatr Surg 1991;26(3): 283-287. DOI: 10.1016/0022-3468(91)90503-L.

13. Chan KL, Hui WC, Tam KH. Prospective, randomized, single-center, single-blind comparison of laparoscopic vs open repair of pediatric inguinal hernia. Surg Endosc 2005;19(7):927-932. DOI: 10.1007/ s00464-004-8224-3.

14. Schier F, Montupet P, Esposito C. Laparoscopic inguinal herniorrhaphy in children: a three-center experience with 933 repairs. J Pediatr Surg 2002;37(3):395-397. DOI: 10.1053/jpsu.2002.30842.

15. Chinnaswamy $P$, Mallabiv V, Jani KV, et al. Laparoscopic inguinal hernia repair in children. JSLS 2005;9(4):393-398.

16. Schier F. Laparoscopic inguinal hernia repair - a prospective personal series of 542 children. J Pediatr Surg 2006;41(6):1081-1084. DOI: 10.1016/j.jpedsurg.2006.02.028.

17. Verma $D$, Ram D, Gupta $M$, et al. Laparoscopic herniotomy-A single centre study of 150 cases. Am J Clin Exp Med 2017;5(5):181-185. DOI: 10.11648/j.ajcem.20170505.15.

18. SpurbeckWW, Prasad R, Lobe TE. Two-year experience with minimally invasive herniorrhaphy in children. Surg Endosc 2005;19(4):551-553. DOI: 10.1007/s00464-004-8922-x.

19. Kastenberg Z, Bruzoni M, Dutta S. A modification of the laparoscopic transcutaneous inguinal hernia repair to achieve transfixation ligature of the hernial sac. J Pediatr Surg 2011;46(8):1658-1664. DOI: 10.1016/j.jpedsurg.2011.03.022.

20. Ozgediz D, Roayaie K, Lee $H$, et al. Subcutaneous endoscopically assisted ligation (SEAL) of the internal ring for repair of inguinal hernias in children: report of a new technique and early results. Surg Endosc 2007;21(8):1327-1331. DOI: 10.1007/s00464-007-9202-3.

21. Takehara H, Yakabe S, Kameoka K. Laparoscopic percutaneous extraperitoneal closure for inguinal hernia in children: clinical outcome of 972 repairs done in 3 pediatric surgical institutions. J Pediatr Surg 2006;41(12):1999-2003. DOI: 10.1016/j.jpedsurg.2006.08.032.

22. Becmeur F, Philippe P, Lemandat-Schultz A, et al. A continuous series of 96 laparoscopic inguinal hernia repairs in children by a new technique. Surg Endosc 2004;18(12):1738-1741. DOI: 10.1007/s00464-004-9008-5.

23. Giseke S, Glass M, Tapadar P, et al. A true laparoscopic herniotomy in children: evaluation of long-term outcome. J Laparoendosc Adv Surg Tech A 2010;20(2):191-194. DOI: 10.1089/lap.2009.0069.

24. Wheeler AA, Matz ST, Schmidt S, et al. Laparoscopic inguinal hernia repair in children with transperitoneal division of the hernial sac and proximal purse string closure of peritoneum: our modified new approach. Eur J Pediatr Surg 2011;21(2):381-385. DOI: 10.1055/s-00311291181.

25. Endo M, Watanabe T, Nakano M, et al. Laparoscopic completely extraperitoneal repair of inguinal hernia in children: a singleinstitute experience with 1,257 repairs compared with cut-down herniorrhaphy. Surg Endosc 2009;23(8):1706-1712. DOI: 10.1007/ s00464-008-0300-7. 